\title{
Six Sigma methodology: an effective tool for quality management
}

\author{
Department of Mechanical Engineering, \\ University of Brescia, \\ via Branze 38, 25123 Brescia, Italy \\ Fax: 00390303702448 \\ E-mail: francesco.aggogeri@ing.unibs.it \\ E-mail: gentili@ing.unibs.it \\ ${ }^{*}$ Corresponding author
}

Francesco Aggogeri* and Enzo Gentili

\begin{abstract}
The quality standards of the output, the features of delivery and the introduction of new services are becoming the most important factors to success in business performance. In this context, the application of new methodologies is essential to increase the business performance. Six Sigma can give an important solution for those companies that intend to highlight the customer satisfaction focusing on the continuous improvement of the processes. The purpose of this paper is to show the power of the Six Sigma methodology in increasing the performance level of industrial processes and systems. The paper shows a Six Sigma case study applied to the automotive market.
\end{abstract}

Keywords: quality management; continuous improvement; problem solving.

Reference to this paper should be made as follows: Aggogeri, F. and Gentili, E. (2008) 'Six Sigma methodology: an effective tool for quality management', Int. J. Manufacturing Technology and Management, Vol. 14, Nos. 3/4, pp.289-298.

Biographical notes: Francesco Aggogeri is part of Technology and Production Systems Research group at the University of Brescia. His research subjects are improvement of processes, implementation of improvement methodologies (Six Sigma, LeanSigma and Scor) and Quality Control. $\mathrm{He}$ is a LeanSigma Expert.

Enzo Gentili is full Professor of Special Technologies at University of Brescia. $\mathrm{He}$ began his research in the field of metal plasticity (wire and tube drawing, deep drawing, forging, extrusion forging and the ring test). His research interests are the use of FEM in metal plasticity and metal cutting optimisation, Total Quality Management, preventive and improving systems for Quality Control and safety management. He is author of several publications and editorial member of a number of journals.

\section{Introduction}

The current dynamism of the market, characterised by an ever-increasing astute cliental, has imposed high performance levels, the assets, as quality standards, prompt delivery 
and the introduction of new innovative products and services are basic for the business company success. Six Sigma can be a strategic tool to gain efficiency in order to satisfy customers.

The introduction of these management philosophies means a wide reorganisation of the company, by adopting continuous improvement logic and assuring severe changes in business results. The end purpose, in adopting the Six Sigma methodology, is to create an output, exactly as desired by the customer, by internally removing all the potential source of defects and reducing no-value activities from the value stream. Six Sigma is an implementation of a measurement system to collect data, analyse results and integrate the information into industrial processes. Six Sigma means that the process or product will perform with almost no defects, but the methodology goes beyond this aspect. In fact, the methodology is a better way to manage a business or a department. It "puts the customer first and uses data and facts to drive a better solution" (Pande and Holpp, 2002). It could be defined at three distinct levels: metric, for an elevated number of data and statistical concepts, methodology, for a rigorous problem-solving method and philosophy, for a new idea to involve all internal and external resources.

The methodology leaves a large field to interpret its adaptability in the different contexts; it delivers a clear structure that could be used and decomposed in many solutions. In the Six Sigma methodology, communication is an important key for success. It is fundamental to involve all aspects of the organisation, showing the philosophy principles, tools and tactics. Over the last years, Six Sigma is becoming a strong reference for the industrial quality and the business management. It is not the continuation of total quality management. In fact, even if the methodologies have the same goals and similar application tools, Six Sigma and total quality management were born in different places and have their own distinct managerial features in a problem-solving approach.

\section{The Six Sigma guidelines}

The Six Sigma methodology is characterised by two different problem-solving methods: the DMAIC (Define, Measure, Analyse, Improve, Control) and the DFSS (Design For Six Sigma). It is possible to use the DMAIC for the already existing processes or the system, while it is preferable to apply the DFSS in optimising a design process (Yang and El-Haik, 2003).

In the Six Sigma projects of this paper, we applied the DMAIC problem-solving method, even if in different project aspects there are a few references to DFSS (Design for Six Sigma). Therefore, in this section the DMAIC features are explained briefly. The DMAIC has five principle phases: define, measure, analyse, improve and control (George et al., 2004).

In the first phase the Six Sigma, leaders (Black Belt and Master Black Belt) define the purpose of project, the members of Six Sigma group, the timetable for actions and the necessary tools to resolve the problem. In the define step, the Six Sigma team analyses the VOC (Voice of the Customer), the customer requirements and needs to identify the CTC (Critical to Customer). In order to follow the Six Sigma roadmap, it is necessary to calculate the CTQs (Critical to Quality). The CTQs are all the features and parts of the process (or the product) that could be critical for the business performance. The CTQs are defined by the assessment of the VOC too. "The activities, that cause the 
customer's critical-to-quality (CTQ) issues and create the longest time delay in any process, offer the greatest opportunity for improvement in cost, quality capital and lead time" (George, 2002). Thus it is important to map the process to know the VOP (Voice Of The Process), the process features and information. In the second phase, the Six Sigma group measures the process to define the capability and the performance (for example $\mathrm{Cp}$ or $\mathrm{Cpk}$ ) by assessing the VOP quantitatively.

The analysis phase has the scope to identify the causes of an unsatisfactory performance. The fourth activity is to improve the process by eliminating the causes and reducing the variability, while the last operation is to check that the obtained results can be maintained in the company. Each month (for example) the team reports on the progress of their process characterisation and improvement studies. It is important to identify the stakeholders that include managers, operators, customers, suppliers and people involved in the process (Federico and Beaty, 2003). Defining, measuring, analysing, improving and controlling the activities of the organisations can increase the efficiency that is gained by improving equipment usage, improving management methods and implementing strategic plans and goals (Adams et al., 2003). Often, these costs absorb a significant share of the sales. Business must satisfy each of the customer's needs, produce quality products at lowest cost possible and sustain acceptable profitability. "The DMAIC roadmap is not only useful for problem troubleshooting; it also works well as a checklist when doing a project" (Brussee, 2004).

The methodology leaves a large field to interpret its adaptability in the different contexts; it delivers a clear structure that could be used and decomposed in many solutions. Its flexibility, if applied correctly, enables a significant improvement and saving in service companies.

\section{The power of Six Sigma}

Sigma defines the performance level of a process, described by a normal distribution level, to satisfy the customer needs. Supposing that a process is centred on the tolerance interval, the level of sigma denotes the distance between the process average and the nearest specification limit. Three sigma processes represent a highly unsatisfactory performance (Brue, 2003), because they generate 2,700 defects per million parts. The goal of the methodology is "to produce at least $99.99966 \%$ 'quality' at 'the process step' or part level within assembly" (Basu and Wright, 2004).

This means no more than 3.4 defects per million parts or process steps if the process has a shift of as much as 1.5 in the long run. It is important to remember that another Six Sigma metric is the capability index, $\mathrm{Cp}$ and $\mathrm{Cpk}$. A Six Sigma quality level assures index values for $\mathrm{Cp}$ and $\mathrm{Cpk}$ requirement of 2.0 and 1.5 , respectively.

\section{Economic impact of Six Sigma}

In order to analyse the economic impact of the Six Sigma methodology, it is necessary to refer to Figure 1. These data were obtained by companies that already apply this methodology. The performance increase is possible by reducing the COPQs (Costs of Poor Quality). The COPQs are "internal failures (scraps and rework), external failures 
(field failures, complaints and returned material), appraisal (inspection and audit) and prevention (quality planning and process control)" (de Feo and Barnard, 2004).

Often, these costs absorb a significant share of the sales. As shown in Figure 1, the COPQs of a Six Sigma process are only $5 \%$ of sales, impacting strongly on the company gains.

Figure 1 The impact of COPQs on sales vs. Sigma level

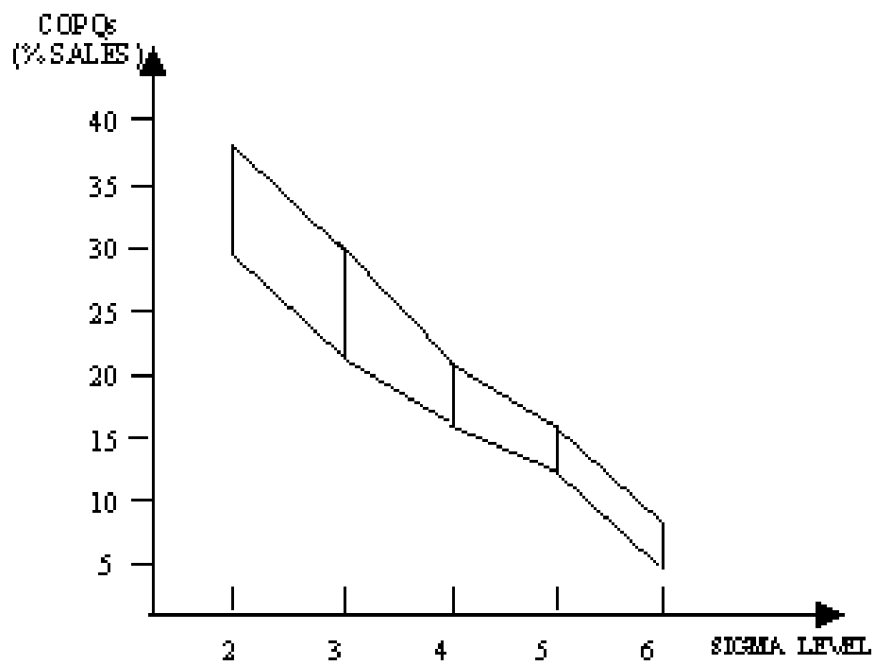

\section{A Six Sigma application: KOMO project}

The purpose of this case study, namely KOMO project, is to show the power of the Six Sigma methodology in satisfying the requirements of the automotive market. The core business of the project company is the production of aircooling devices for deluxe vehicles. The project highlights a review of the manufacturing systems to eliminate the scraps due to the high quality standards of a deluxe market.

For the project, it was very important to collect input information on customer needs and expectations, translate the VOC input into meaningful terms and define requirements for the process and product. The project product is shown in Figure 2.

Figure 2 The project product, an air-cooling pipe
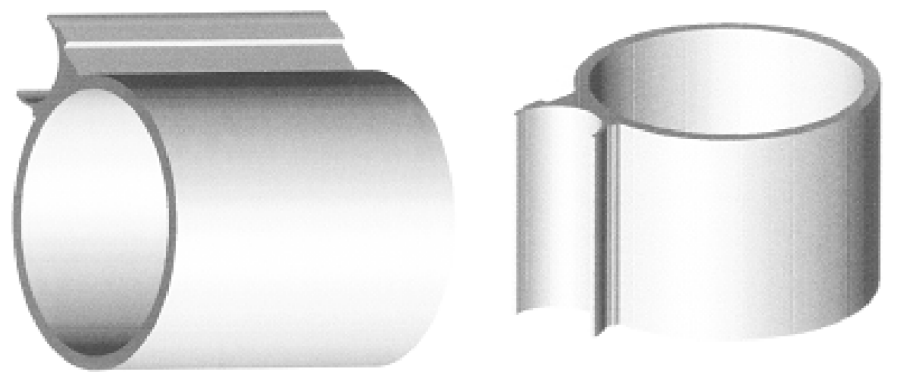


\subsection{The project definition}

In modern organisations, processes are fragmented in different departments. The team should map the primary process and alternative paths, providing a context picture. In this way, information and data are the inputs (CTQ) for the other Six Sigma steps.

To understand the complexity of the KOMO system, a process mapping was necessary. Thus, the production stream of the product is described: the extruded pipes arrive at the warehouse from the supplier, and then they are transported to the cutting process.

In this position, an operator cuts the pipes in devices of $400 \mathrm{~mm}$ and eliminates the produced chips. The devices are worked by five machine tools producing on the piece all features required by the customer. Subsequently the devices, having been washed in an industrial washing machine, are sent to a DC (distribution centre) that then delivers them to the vehicle constructors. In order to verify customer's requirements, a $100 \%$ sampling was implemented in the distribution centre, using a visual inspection.

The applied problem-solving method was the DMAIC (Define, Measure, Analyse, Improve, Control), but in certain project aspects there are references to DFSS (Design for Six Sigma). In order to deploy this project, the top management had constituted a team, consisting of the production manager, the control and assurance quality leader, two expert operators and continuous improvement consultants. It was essential to make an effective use of the main human resources of the company. In the first part of the study, it was necessary to collect information and data concerning the manufacturing system.

The tools used to collect information on the Voice of the Customer "include many simple and sophisticated market research methods, requirement analysis concepts, and newer technologies, such as data warehouses and data mining" (Pande and Holpp, 2002). This activity was divided into two steps:

- to assess the technical reports of the Distribution Centre, classifying the main defect categories and deploying an economic analysis on the Cost of Poor Quality and on the lost gains

- the implementation of an internal visual inspection to check the impact of the Six Sigma actions in order to understand if there was an effective improvement of the system performance level.

Considering this information, it was possible to plan the main milestones for the improvement actions.

The first step of the project was to identify the CTCs (Critical to Customer), assessing the technical reports given by the DC inspection. The collection of these data and information allowed us to constitute a defect list, as follows: blows on device, off centring error, internal roughness, extrusion bubbles and scraps on device that represented the CTCs (Critical to Customer).

A Pareto diagram identified that the main defect category was blows on device, followed by extrusion bubbles. These customer needs had to be correlated with the Critical to Quality (CTQs) characteristics, using the Quality Function Deployment, developed by the Six Sigma team, Table 1.

This tool can be used to link the Voice of the Customer directly to internal process. It involves the entire company in the design and control activity, reporting the Critical to Customer information and comparing it with the Process and the Product (Pyzdek, 2003). 
The CTCs are in the rows while the CTQs, the features of the process or product giving value to customer satisfaction, are in the columns.

This first qualitative analysis showed that the Six Sigma team had to focus on the washing process and in particular on the industrial washing machine with reference to the extremity zone of the piece.

Table 1 The QFD for KOMO project

\begin{tabular}{lccccc}
\hline & $\begin{array}{c}\text { Extremity zone } \\
\text { of piece }\end{array}$ & Cutting & Washing & Machine tool & Priority level \\
\hline $\begin{array}{l}\text { Blows on } \\
\text { device }\end{array}$ & 10 & 5 & 10 & 4 & 7 \\
$\begin{array}{l}\text { Extrusion } \\
\text { bubbles }\end{array}$ & 1 & 1 & 1 & 1 & 5 \\
$\begin{array}{l}\text { Off centring } \\
\text { error }\end{array}$ & 1 & 1 & 1 & 8 & 3 \\
$\begin{array}{l}\text { Internal } \\
\text { roughness }\end{array}$ & 1 & 1 & 1 & 1 & 1 \\
$\begin{array}{l}\text { Scraps on } \\
\text { device }\end{array}$ & 8 & 10 & 8 & 5 & 3 \\
Total & 103 & 74 & 103 & 73 & \\
\hline
\end{tabular}

The last part of the define phase consisted in an economic analysis of the KOMO project. The production cost of a piece is $4 €$ and the transportation fee of the devices rejected by the DC is $0.5 € /$ piece. Considering a production volume of $60,000,000$ pieces/year, it is possible to quantify the COPQs measuring the performance level of the KOMO system, as follows.

\subsection{The measurement phase}

The measure phase is mainly concerned with identifying the key customers, determining what their critical needs are, and what are the measurable CTQs necessary for a successfully designed product (De Feo and Barnard, 2004). Measures are important because they help in creating baselines and targets for improvement, and provide a common language and focus for a cross-functional group (Stamatis, 2002). In fact, the measurement shows us how the reduction of defects and the elimination of the variability give a link to a correct collection of data and information.

Analysing the Distribution Centre reports on defects, it was possible to calculate the KOMO system yield. Considering a production volume of 60,000,000 pieces/year, it was $98.5 \%$ defining 900,000 defect pieces/year. In order to check the impact of the improvement actions, the Six Sigma Team implemented a visual inspection $(100 \%$ sampling) after the washing process. Nevertheless, in the first analysed batch they rejected lot of pieces as scraps, without classifying them in a particular defect category. This aspect highlighted that an inspection training was necessary to improve the performance level of the measurement system. 


\subsection{The analysis phase}

The analysis phase was divided into two steps: manufacturing processes, considering the machinery and all internal features of the system, and materials, involving the supplier processes and external resources. To begin the Six Sigma team considered blows on device as the main defect category, because it had a strong impact on the final result. In order to assess the scraps, the team studied those piece zones in which there were a lot of blows, identifying the extremity of the device as a critical area on which the team should focus for immediate improvement, as shown in the qualitative analysis (QFD). A global review of the system enabled us to identify the washing machinery as a defect source. In fact, the machinery basket could damage the device when the operator inserts the piece into the machinery, as shown in Figure 3.

Figure 3 Washing simulation before Six Sigma implementation

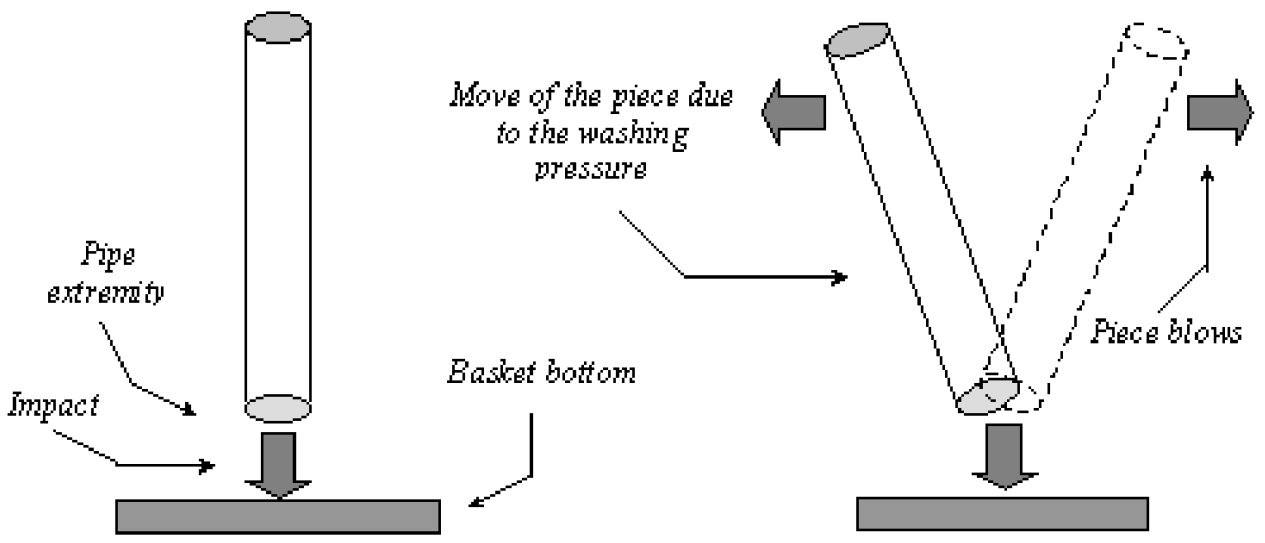

The brainstorming analysis focused on the other defect categories; for example it was possible to note that the scraps on the device could be caused by the cutting process and in particular by the maintenance of the cutter. The bad clamping of the piece in the machine tools could give rise to the off centring errors. To identify the source of the extrusion bubbles, the Six Sigma team involved the pipe supplier, imposing on it a global review of its processes. This step was deployed by the marketing managers, defining the main operative milestones to reach the performances requested by the automotive market. It was essential to study the performance level of the inspection process. In fact in the first measurements, the operators classified many pieces in the unknown defect category. Thus, a training for operators to define the real defect classes was necessary.

\subsection{The improvement and control phases}

The first step of the improvement phase was the deployment of a new training to show the operators the different typologies of defects. This action reduced strongly the 'unknown' category. Before the Six Sigma application, the 'unknown' voice was $13 \%$ in the defect classification and $2.3 \%$ in methodology implementation.

In order to eliminate the blows on the device, the Six Sigma team studied a new method to wash pieces, by changing the basket cover. This choice enabled us to protect the pieces during the washing, eliminating the blows on the device. The maintenance 
person used rubber to cover the basket that softens the blows owing to water pressure during the washing. Figure 4 shows the washing basket before the Six Sigma analysis (a) and after the implementation of the improvement actions.

Another important step was to involve the pipe supplier, in order to eliminate the extrusion bubbles. The Six Sigma team imposed a global review of the process, suggesting a deployment of the DOE (Design of Experiments). Using the Design of Experiment, it was possible to identify which process variables had a strong influence of the final result. The team suggested checking the extrusion speed and temperature. At present the analysis of these data are in the process of being worked. Nevertheless the first results of this study are shown in the last visual inspection measurements. In implementing Six Sigma, the company obtained these results: the KOMO system yield was $98.50 \%$ and, at present, the results of the last measurements show that the new yield is $99.45 \%$

Figure 4 (a) The washing basket before and (b) after the cover
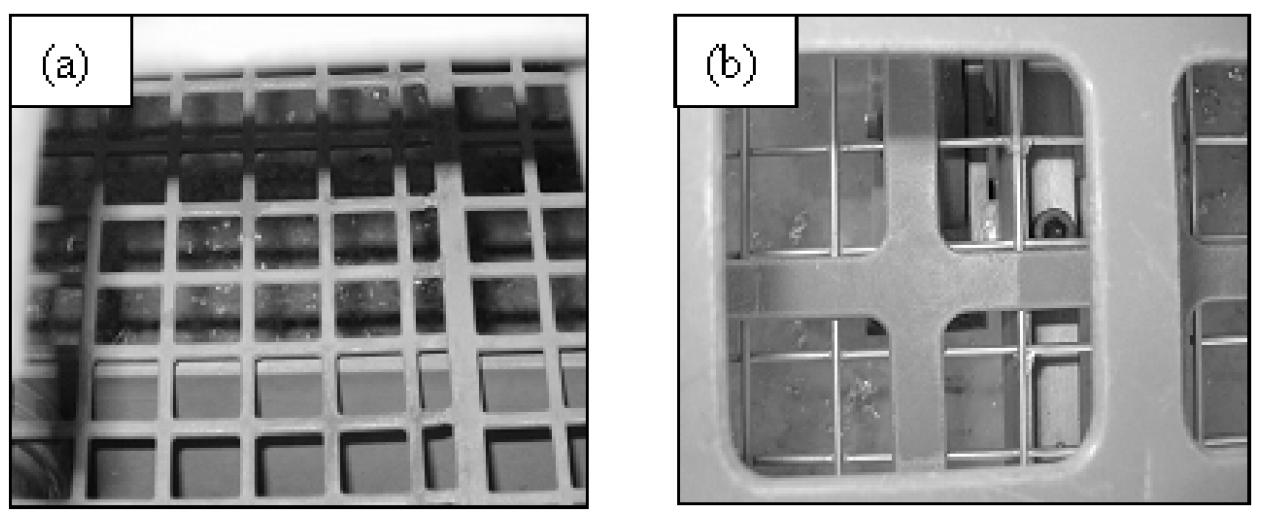

\subsection{Beyond DMAIC in the KOMO project}

The Six Sigma methodology provides a problem-solving method to design product and process, utilising tools, training and measurements. The design purpose is to meet customer expectations at Six Sigma quality levels. The name of this problem-solving method is Design for Six Sigma and this can be integrated in the DMAIC. As just stated the framework deploys five phases: define, measure, analyse, design and verify (DMADV). In the KOMO project the team used prevalently the DMAIC, but in some situations, there was the possibility to design new elements or activities for the system.

For example, during the analysis phase the team assessed the possibility of moving the washing process to the centre of the layout reducing the cycle time and avoiding the blows and scraps because of internal transportation. This action is not easy to implement. Nevertheless, the team is working to fulfil this expectation. In collaboration with the Distribution Centre (DC), the company is analysing the possibility of eliminating the visual inspection in the DC. Before the Six Sigma implementation, the more expert operators were on the washing process in order to avoid the scraps on the pieces. Now it is possible to use them in the company's internal inspection process, reducing the costs owing to rejected batches. The main problem of Design for Six Sigma is the 
implementation time. In the KOMO project a high quality standard was required in a short time.

\subsection{The economic analysis}

Before the Six Sigma implementation the KOMO system yield was $98.5 \%$ with a COPQ of 3,600,000 €/year (considering a production volume of 60,000,000 pieces/year and a production cost of $4 € /$ unit). The implementation of the methodology gave the new process yield of $99.45 \%$ (330,000 defects/year), with a COPQs of 1,320,000 $€ /$ year and a saving of $2,280,000 € /$ year. It is possible to consider the elimination of the visual inspection in the Distribution Centre. Supposing an average transportation cost of $0.5 € /$ year, the company saving is $165,000 € /$ year. Therefore the total company saving is $2,445,000 € /$ year, underlining that there are no investments in the project.

\section{Conclusions}

Six Sigma is a smarter method to manage a company focusing on customer satisfaction and using data and facts to achieve better solutions. This project underlines the Six Sigma effectiveness and flexibility. The methodology assures an increased customer loyalty, more revenues, higher returns and increased earnings.

Six Sigma is more than a process improvement. It is part of a planned and monitored business strategy geared towards success. The major key to obtain its successful implementation is the alignment of the organisation's visions, values and systems. Thus, it is also fundamental to identify the sources of resistance to Six Sigma and planning a strategy to overcome that resistance (Adams et al., 2003). The application of Six Sigma confirms that this approach is essential in satisfying the customer need requirements in reducing costs. This paper intends to show the particular method of approaching industrial problems, independent of their nature enabling the company to guarantee the satisfaction of customer needs at the lowest possible cost. In this project, there are no significant investments in fact the team took advantage only of resources that already existed in the company. Six Sigma should not replace existing organisational initiatives, but instead create an infrastructure that offers a tactical approach to determinate the best solution for a given situation (Breyfogle and Meadows, 2000).

In this way, the reduction of the COPQs is assured in short time. We can conclude that Six Sigma is an application to increase the business performances and to improve management operations. It enables employees to deliver the greatest value to customers and owners. The power of the methodology is the possibility to quantify the results of its application as company savings or profitability. This aspect is often neglected in other improvement techniques.

The organisational mistake is often to think that the methodology is only a statistical technique. Six Sigma is more than a statistical method, which is a part of business strategy that involves all company stakeholders. It is also wrong to think that Six Sigma can be applied only in multinational companies; its implementation is possible in every industrial context. 


\section{Acknowledgments}

The Authors wish to acknowledge the generous support offered by MIUR in the realisation of this work. Special thanks to Mrs. Mary Flynn who checked the manuscript.

\section{References}

Adams, C., Gupta, P. and Wilson, C. (2003) Six Sigma Deployment, Butterworth Heinemann, Amsterdam.

Basu, R. and Wright, J.N. (2004) Quality Beyond Six Sigma: 36, Butterworth Heinemann, New York.

Breyfogle III., F.W. and Meadows, B. (2000) The Six Sigma Implementation Process, www.smartersolution.com, Smarter Solution Inc.

Brue, G. (2003) Six Sigma for Manager: 4, McGraw-Hill, New York.

Brussee, W. (2004) Statistics for Six Sigma Made Easy!: 13, McGraw-Hill, New York.

de Feo, A. and Barnard, W. (2004) Juran Institute's Six Sigma: 25-73, McGraw-Hill, New York.

Federico, M. and Beaty, R. (2003) Six Sigma Team Pocket Guide, McGraw-Hill, New York.

George, M. (2002) Lean Six Sigma: 4, McGraw-Hill, New York.

George, M.L., Rowlands, D., Price, M. and Maxey, J. (2004) Lean Six Sigma Pocket Toolbook, McGraw-Hill, New York.

Pande, P. and Holpp, L. (2002) What is Six Sigma?, 56, McGraw-Hill, New York.

Pyzdek, T. (2003) The Six Sigma Handbook, McGraw-Hill, New York.

Stamatis, D.H. (2002) Six Sigma and Beyond Foundations of Excellent Performance, St. Lucie Press, New York, Vol. 1, p.120.

Yang, K. and El-Haik, B. (2003) Design for Six Sigma, McGraw-Hill, New York. 